Pteridines

Vol. 17, 2006, pp. $105-106$

\title{
Neopterin Screening of Blood Donations
}

\author{
Vojtech Parrak, Peter Secnik², Marcela Skrakova' \\ 'St. Cyril and Method University Hospital, Petrzalka, Bratislava; ${ }^{2}$ General Regional Hospital, Lucenec, Slowakia
}

\section{To the Editor:}

The sensitivity of neopterin testing to detect acute virus infections was investigated recently in commercial seroconversion panels (1). In sera positive by viral nucleic acid amplification technologies (NAT), a high frequency of increased ncoptcrin levels was only found in human immunodeficiency virus (HIV) but not in hepatitis B and $\mathrm{C}$ virus infections. Authors conclude that introduction of additional neopterin screening is not supported by their data. However, this conclusion is not justified for HIV when NAT is not performed as it is the case in many countries, and it is probably also not true for other virus infections.

In the Slovak Republic the transfusion processing is regulated by law (3878/93-B/1-Z from 10.08.1993), and each blood unit has to be examined with the following laboratory tests: blood group, blood picture, Kell antigens, HIV1 and -2 antibodies, HCV antibodies, HbsAg, ALT (GPT), and Lues serology. As in many other countries, NAT is not performed routinely. Thus according to the data by Nuebling et al., additional neopterin screening would still reduce HIV transmission risk in Slovakia. Moreover, when we retrospectively determined neopterin concentrations in 11,915 blood donors (8687 males, 3228 females; average age 30.4 years) from St.Cyril and Metod Hospital, Bratislava and General Regional Hospital, Lucenec, we can further support the conclusion that neopterin screening would reduce the risk of Epstein-Barr virus (EBV) and cytomegalovirus (CMV) infection by way of blood transfusion. We noticed very good analytical performance of the ELISA used (provided by BRAHMS, Hennigsdorf, Germany), and average neopterin concentration was $5.02 \mathrm{nmol} / \mathrm{L}$ which agrees well with data in the literature (2). In the 165 donations with neopterin concentration above $10 \mathrm{nmol} / \mathrm{L}(=1.4 \%$ of all samples tested), the frequency of EBV $(3 / 165=1.8 \%)$ and CMV $(11 / 165=6.7 \%)$ IgM seropositivity by ELISA (Behring, Marburg, Germany) was significantly higher than in 360 donations matched for sex and age, and for the time and location of blood donation with normal neopterin in which no seropositive samples were detected ( $p$ $<0.01$ for EBV and $\mathrm{p}<0.001$ for CMV; Fisher's exact test: Table 1). Also these results well confirm earlier fin-

Table 1: CMV and EBV $\operatorname{lgM}$ seropositivity in 165 blood donations with neopterin concentrations above $10 \mathrm{nmol} / \mathrm{L}$ out of 11,915 tested $(1.4 \%)$ and in a control group of 360 donations matched for sex and age, and for the time and location of blood donation. ( $\mathrm{p}<0.01$ for EBV and $\mathrm{p}<0.001$ for CMV; Fisher's exact test).

\begin{tabular}{|c|c|}
\hline \multicolumn{2}{|c|}{ Seropositivity } \\
\hline CMV IgM & EBV IgM \\
\hline $11(6.7 \%)$ & $3(1.8 \%)$ \\
\hline
\end{tabular}

dings published from Austria (3-5). As stated by Nuebling et al., additional neopterin screening of blood donations was introduced in Austria because it should serve like a shield which reduces the transmission risk of viruses which are not specifically screened for and it should also provide a barrier also for new agents. Our own data are in line with this concept.

In conclusion, data presented by Nuebling et al. on increased neopterin concentrations in antibody negative but NAT positive seroconverter panels do rather support the introduction of neopterin testings of blood donations especially in countries in which NAT is not routinely in use.

Correspondence to: Vojtech Parrak, St. Cyril and Method University Hospital, Antolska II, Petrzalka, 85107 Bratislava, Slovak Republic, e.mail: parrak@npba.sk 


\section{References}

1 Nuebling CM, Chudy M, Volkers P, Lower J. Neopterin levels during the early phase ofhuman immunodeficiency virus, hepatitis $\mathrm{C}$ virus, or hepatitis $B$ virus infection. Transfusion 2006;46:188691.

2 Hönlinger M, Fuchs D, Hausen A, et al. SerumNeopterinbestimmung zur zusätzlichen Sicherung der Bluttransfusion. Deutsch Med Wochenschr 1989;114:172-6.

3 Hönlinger M, Fuchs D, Reibnegger G, Schönitzer D, Dierich MP, Wachter H. Neopterin screening and acute cytomegalovirus infections in blood donors. Clin Investig 1992;70:63.
4 Schennach H, Hessenberger G, Mayersbach P, Schönitzer D, Fuchs D. Acutecytomegalovirus infections in blood donors are indicated by increased scrum neopterin concentrations. Med Microbiol Immunol 2002;191:115-8.

5 Schennach H, Mayersbach P, Schönitzer D, Fuchs D, Wachter $\mathrm{H}$, Reibnegger $\mathrm{G}$ : Increased prevalence of IgM antibodies to Epstein-Barr virus and parvovirus B19 in blood donations with above-normal neopterin concentration. Clin Chem 1994;40:21045. 